\title{
Morphological and Structural Study of Anodized Titanium Grade 2, Using HCl in Aqueous Solution
}

\author{
A. Maytorena-Sánchez ${ }^{a}$ (D), J. Hernández-Torres ${ }^{a}$, R. Orozco-Cruz ${ }^{b}$, L. Zamora-Peredo ${ }^{a}$, \\ F. López-Huertac, M. Pacio-Castillo ${ }^{d}$, L. E. Serrano-de la Rosa ${ }^{e}$, L. García-Gonzáleza,* (D) \\ ${ }^{a}$ Universidad Veracruzana, Centro de Investigación en Micro y Nanotecnología, Adolfo Ruíz Cortines \\ 455, Veracruz, México. \\ ${ }^{b}$ Universidad Veracruzana, Instituto de Ingeniería, Adolfo Ruíz Cortines 455, Veracruz, México. \\ 'Universidad Veracruzana, Facultad de Ingeniería Eléctrica y Electrónica, Adolfo Ruíz Cortines 455, \\ Veracruz, México. \\ ${ }^{d}$ Benemérita Universidad Autónoma de Puebla, Centro de Investigación en Dispositivos, San Claudio, \\ Puebla, México. \\ eBenemérita Universidad Autónoma de Puebla, Instituto de Física, San Claudio, Puebla, México.
}

Received: September 25, 2021; Revised: January 17, 2022; Accepted: January 19, 2022

In this work, the electrochemical anodization process was carried out on titanium grade 2, using an electrolytic solution of $3 \mathrm{M}$ and $0.15 \mathrm{M} \mathrm{HCl}$ with voltages of $11 \mathrm{~V}, 12 \mathrm{~V}$ and $15 \mathrm{~V}$, as well as time variations in the experimental process and later an annealing process at $750{ }^{\circ} \mathrm{C}$. According to the results obtained, the $\mathrm{TiO}_{2}$ coatings presented different morphologies on their surface, which consisted of nanopores, nanowires and clusters of oxide grains, as well as a combination of anatase and rutile crystalline phases. Band Gap variations were found to be non-significant despite changes in the morphology of the coatings at different anodization conditions, with an average value of $2.91 \mathrm{eV}$. It was observed that the anodized samples treated by the annealing process at $750{ }^{\circ} \mathrm{C}$, thickness values up to $16 \mu \mathrm{m}$ were obtained.

Keywords: Electrochemical anodization, $\mathrm{HCl}$, nanostructures, Titanium Grade 2, $\mathrm{TiO}_{2}$.

\section{Introduction}

Titanium is widely used material in the medical field and in a wide range of technological fields. Titanium has a low density and high corrosion resistance with good plasticity and mechanical properties and is also characterized by its biocompatibility due to the formation of spontaneous passive layers ${ }^{1}$. These materials are mainly used in the aeronautical, maritime, chemical and energy industries ${ }^{2}$. There are several reports for obtaining $\mathrm{TiO}_{2}$ using different synthesis techniques, among them, chemical vapor deposition, sputtering, hydrothermal synthesis, sol-gel, electrochemical methods and spray pyrolysis techniques ${ }^{3}$. Titanium oxide films produced by anodic oxidation have been reported to have more uniform nanoporous and nanotubular structures ${ }^{4}$. According to the materials used for the anodizing process, it is possible to classify the electrolyte solutions into four generations that are correlated for the study of titanium anodization ${ }^{5,6}$. For this particular study, the fourth generation was considered, in which the presence of chloride ions during the anodizing process helps the formation of nanostructures over the outside of the material, in particular, nanopores and $\mathrm{TiO}_{2}$ nanotubes ${ }^{7-14}$.

It has been reported that the use of electrolytes with $\mathrm{F}^{-}$ions can generate safety problems, toxicity or other concerns for industrial scale applications, and ways have been sought to improve the anodizing method by using non-precious metal electrodes and environmentally benign electrolytes for the

*e-mail: leagarcia@uv.mx preparation of $\mathrm{TiO}_{2}$ nanotube films ${ }^{7}$. The anodized materials are characterized by the formation of nanostructures on the oxide layer, which can obtain several properties such as the increase in their hardness values, improvement of their tribological properties ${ }^{12,15}$ and also be used for photocatalytic and biological applications, sensors, photoelectrochemical hydrogen generation and solar cells ${ }^{7-11,13-15}$. The formation of $\mathrm{TiO}_{2}$ nanostructures are generated by a series of steps during the anodizing process. For the first step of formation of nanostructures on the surface of titanium, an oxidation process occurs due to the presence of dissolved $\mathrm{OH}^{-}$ions, the titanium is ionized with a positive charge that attracts these ions and generates the growth of a layer of negative ions, likewise, $\mathrm{Cl}^{-}$ions are also involved in this process. Subsequently, the saturation of negative materials leads to a reversal of the charge, and due to the growth of the non-conductive $\mathrm{TiO}_{2}$ layer, the second stage begins with the dissolution of the negative ions involved by means of the reaction with the positive $\mathrm{H}^{+}$and/ or $\mathrm{H}_{3} \mathrm{O}^{+}$ions, thus generating the formation of possible pores on the oxidized surface ${ }^{12}$. In this study, the electrochemical anodization technique was used to obtain $\mathrm{TiO}_{2}$ nanostructures from $\mathrm{HCl}$ as electrolyte solution, varying the voltage and anodization time, at different concentrations, at 0.15 and $3 \mathrm{M}$, at room temperature, since there is very little reported in the literature the analysis of morphology, microstructure and optical properties of titanium grade 2 anodized with electrolytes based on chloride ions. 


\section{Materials and Methods}

Preparation of anodizing

\subsection{Preparation of the titanium plate}

For electrochemical tests, grade 2 titanium plates with dimensions of $1 \mathrm{~cm} \times 2 \mathrm{~cm}$ and with a thickness of approximately $0.15 \mathrm{~cm}$ were used. Titanium plates were polished with silicon carbide sandpaper from 100 to 2000 . They were then cleaned in an ultrasonic bath with ethanol and deionized water for 5 minutes for each solution and air dried. Also, cathode copper with a thickness of $0.03 \mathrm{~cm}$ was used. Similarly, the cleaning process was carried out with ethanol and deionized water in an ultrasonic bath.

\subsection{Preparation of the electrolytic solution}

The electrolyte was prepared using hydrochloric acid in aqueous solution at different concentrations $(0.15$ and $3 \mathrm{M})$, based on the literature consulted ${ }^{7,13}$. Reagents such as hydrochloric acid and deionized water were Golden Bell Reagents.

\subsection{Generation of the electrolytic cell}

With the GOPHERT power supply, model CPS-3205 II, the titanium was connected to the positive charge (working electrode) and a copper plate to the negative charge (counter electrode), both electrodes were partially immersed in the solution to generate the cell. The titanium anodizing was performed with 11 and $12 \mathrm{~V}$ potentials for a concentration of $3 \mathrm{M}$ since, according to the literature consulted at high concentrations ${ }^{13}$, one should work at low voltages to avoid the corrosion process. Likewise, for a concentration of $0.15 \mathrm{M}^{7}$, we worked at $15 \mathrm{~V}$, because the electrolyte concentration is low. To obtain an oxide layer with a nanostructured surface, the anodizing times were $10 \mathrm{~min}$ for a $3 \mathrm{M}$ concentration with 11 and $12 \mathrm{~V}$, while for a concentration at $0.15 \mathrm{M}$ and $15 \mathrm{~V}$, we worked with times of 10, 30 and $60 \mathrm{~min}$.

\subsection{Heat treatment}

After the electrochemical anodization process, a heat treatment process of the anodized samples was carried out in a Yamato muffle at a temperature of $750{ }^{\circ} \mathrm{C}$ for $2 \mathrm{~h}$, at atmospheric pressure and natural cooling. According with several reports ${ }^{1,2,16-18}$, the process of diffusing oxygen over the surface of the titanium at temperatures above $700{ }^{\circ} \mathrm{C}$ results in the formation of $\mathrm{TiO}_{2}$ in the form of rutile. However, with an anodizing process prior to heat treatment, synthesis by electrochemical anodizing promotes the formation of anatase ${ }^{16}$.

\subsection{Characterization}

\subsubsection{Field emission scanning electron microscopy}

Morphological analysis of the oxide coating generated on grade 2 titanium was performed in a JEOL JSM-7600F field emission scanning electron microscope (FE-SEM). For this analysis, a secondary electron detector (SE) was used and with a voltage of $5 \mathrm{KV}$, the structural changes generated on the anodized surface were analyzed. Images were obtained at 3000, 10000, 30000 and 50000x magnifications. The different morphologies were measured with ImageJ software, with a total of 10 measurements per image of each modified surface to obtain the average size of the nanostructures.

\subsubsection{X-ray diffraction}

The structural studies of the oxide layer were carried out with a Bruker brand X-ray diffractometer, model D8 Advance, with a radiation source $\mathrm{CuK} \alpha=1.5406 \AA$, with which it was possible to obtain the crystalline phases and the size of the crystallite present on the surface of oxidized grade 2 titanium.

\subsubsection{Ultraviolet Visible Spectroscopy (UV-Vis)}

To investigate the optical properties of the generated oxide layer, absorbance was measured using a Thermo Scientific Evolution $600 \mathrm{UV}$-Vis Spectrophotometer, in the range of 250 to $850 \mathrm{~nm}$. The Band-Gap of the oxide layer was also obtained for the anodized samples.

\subsubsection{Profilometry}

A Dektak 150 profilometer was used to obtain the thicknesses of the unheated and heat-treated anodised samples. This instrument allows the measurement of film thicknesses below $100 \AA$ and with dimensions up to 5 inches wide and 4 inches thick. For this process, part of the oxide layer generated was removed using concentrated HF to generate a step on the surface to obtain the thicknesses.

\section{Results and Discussion}

\subsection{Scanning electron microscopy}

An analysis of the morphological changes of the surface of the anodized titanium was carried out under different experimental conditions. Figure 1 shows images of grade 2 titanium polished before surfacing at different anodizing conditions at 3,000 and 10,000x magnifications.

The formation of nanostructures on the surface of anodized titanium was observed at a concentration of $3 \mathrm{M}$ at $11 \mathrm{~V}$ in $10 \mathrm{~min}$, which can be seen in Figure 2 with magnifications of 30,000 and 50,000 x. It can be seen that the anodized surface showed a certain degree of homogeneity in the growth of nanopores, this behavior is similar to that reported in the literature where they also use $\mathrm{HCl}$ as an electrolyte solution ${ }^{12}$. Subsequently, the dimensions of the nanostructures were measured using ImageJ software. An average diameter of the nanopores of approximately $76 \pm 13 \mathrm{~nm}$ was obtained.

In Figure 3, a $3 \mathrm{M}$ and $12 \mathrm{~V}$ concentration in $10 \mathrm{~min}$ of anodizing, the presence of nanostructures was shown in the form of little rocks, but in smaller quantities. The formation of nanostructures was not well defined, even though it was the same electrolytic concentration, the voltage increase did not promote the porous growth contrasted with less voltage (11 V). Therefore, the biggest average agglomeration size was $464 \pm 29 \mathrm{~nm}$, while the smallest agglomeration size was around $70 \pm 10 \mathrm{~nm}$.

In Figure 4, with a $0.15 \mathrm{M}$ and $15 \mathrm{~V}$ concentration in 10 and 30 min of anodization, a nanostructure formation can be seen over the oxidized surface, within 30 min nanowires can be seen.

In Figure 5, with a concentration of $0.15 \mathrm{M}$ and $15 \mathrm{~V}$ in $60 \mathrm{~min}$ of anodization, a greater homogeneity surface on the oxide layer was obtained, yielding to nanoporous 


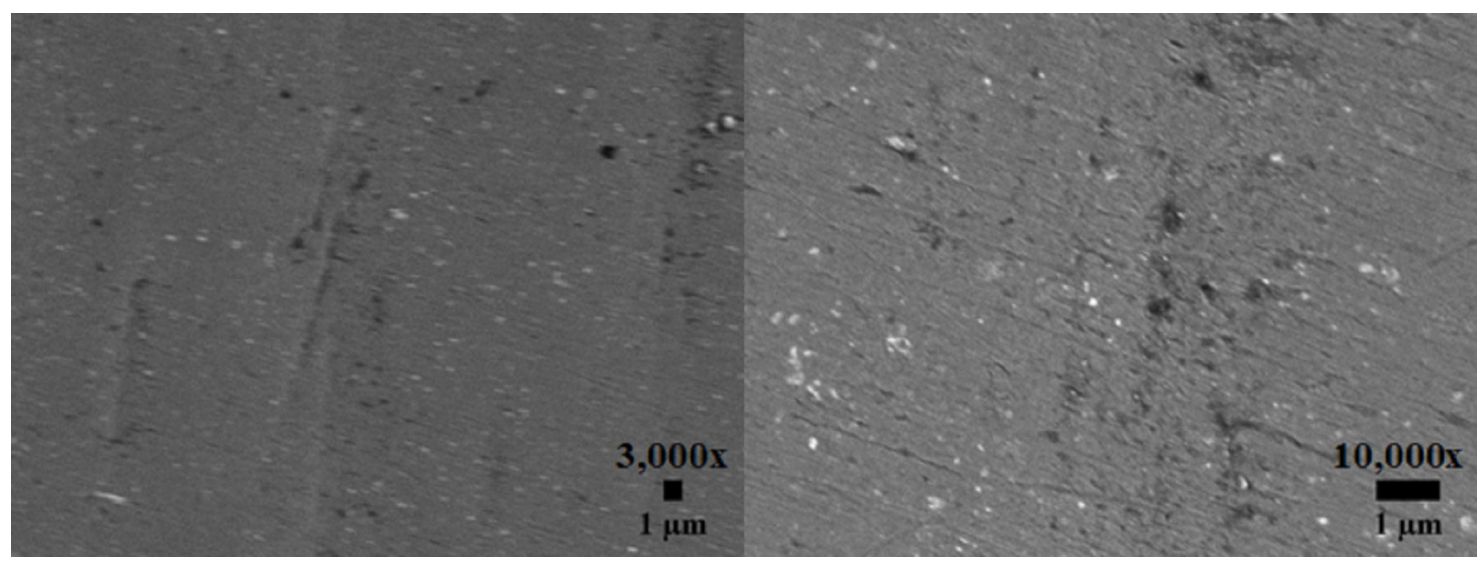

Figure 1. Images of unoxidized grade 2 titanium surface.

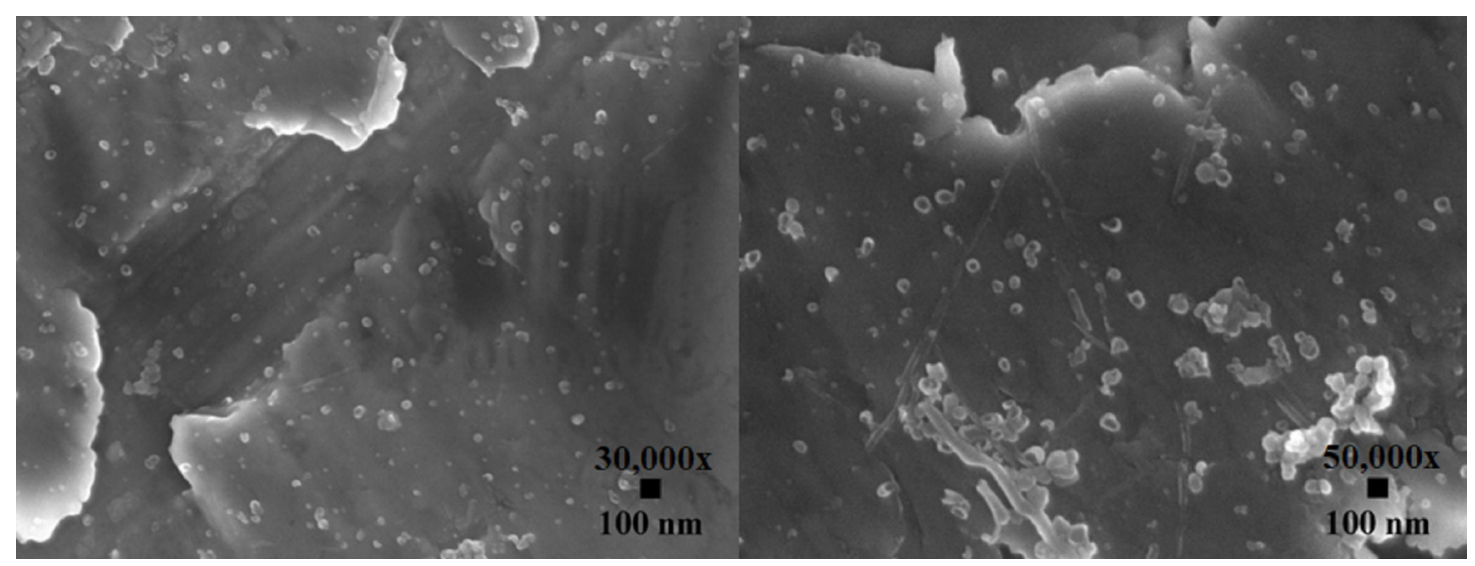

Figure 2. Nanopores over anodized titanium surface with $\mathrm{HCl}$ at $11 \mathrm{~V}$ with a $3 \mathrm{M}$ concentration in $10 \mathrm{~min}$.

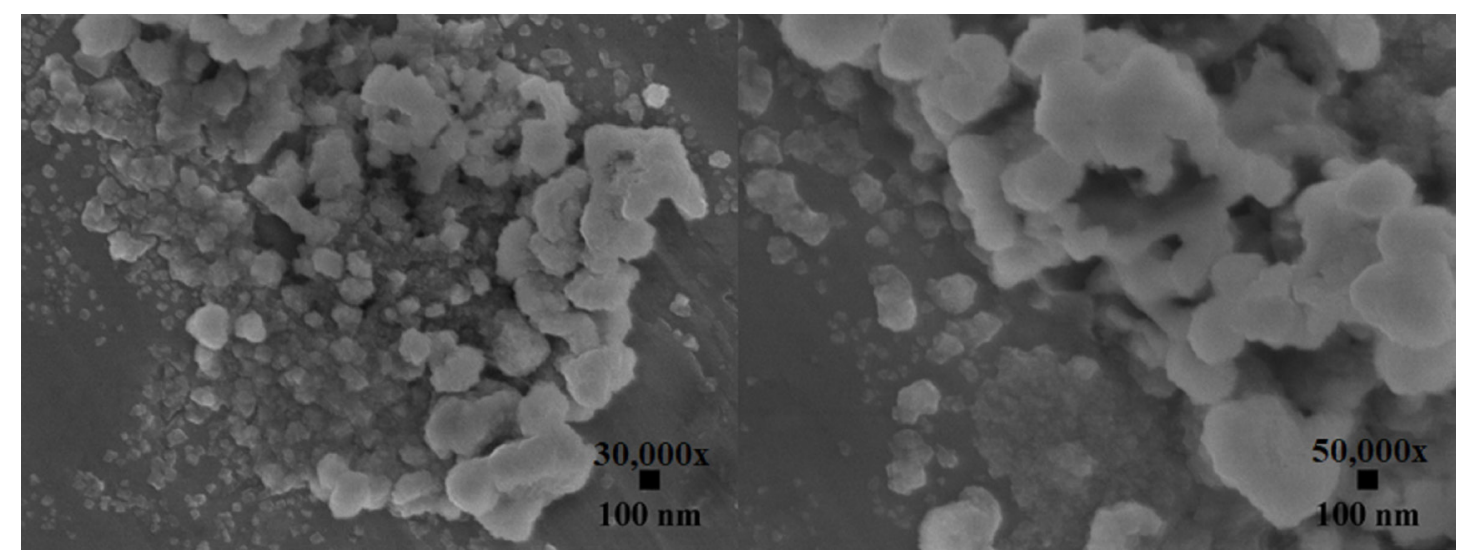

Figure 3. Nanostructures over the surface of anodized titanium with $\mathrm{HCl}$ at $12 \mathrm{~V}$ with a concentration of $3 \mathrm{M}$ in $10 \mathrm{~min}$.

growth over almost all the anodizing area, despite not using a great $\mathrm{HC} 1$ concentration, the anodizing time was a very important factor to get a nanostructured surface. The average nanoporous size was $46.4 \pm 21 \mathrm{~nm}$.

Figure 6 shows the anodized titanium micrographs of $0.15 \mathrm{M}$ with $15 \mathrm{~V}$ with a $60 \mathrm{~min}$ time, which was thermally treated in a $750{ }^{\circ} \mathrm{C}$ annealing process for 2 hours. In Figure 6 , it can be observed that the thermal treatment promoted the generation of oxide crystals on the modified surface, this behavior is similar to that reported in the literature, where through the thermal oxidation process titanium oxide crystals begin to appear from $600{ }^{\circ} \mathrm{C}^{1,2,17-19}$. It can also be noted that the crystal growth 


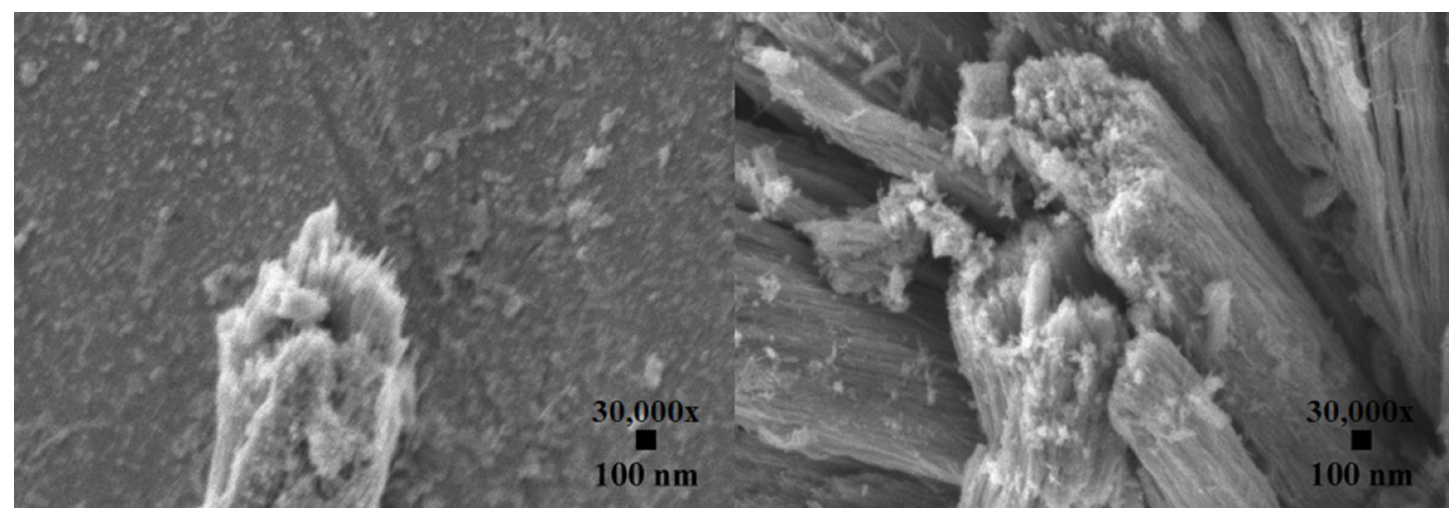

Figure 4. Nanostructures over the surface of anodized titanium with $\mathrm{HCl}$ at $15 \mathrm{~V}$ with a concentration of $0.15 \mathrm{M}$ in a) 10 min and b) 30 min of anodization.

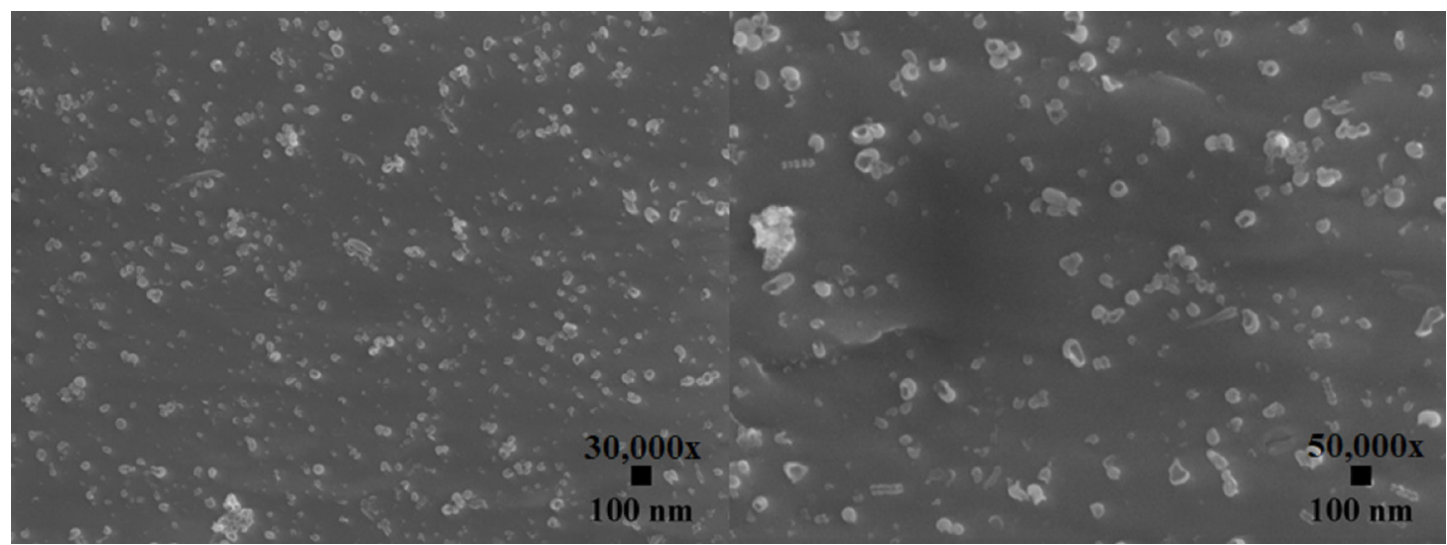

Figure 5. Nanostructures over the surface of anodized titanium with $\mathrm{HCl}$ at $15 \mathrm{~V}$ with a concentration of $0.15 \mathrm{M}$ in $60 \mathrm{~min}$.

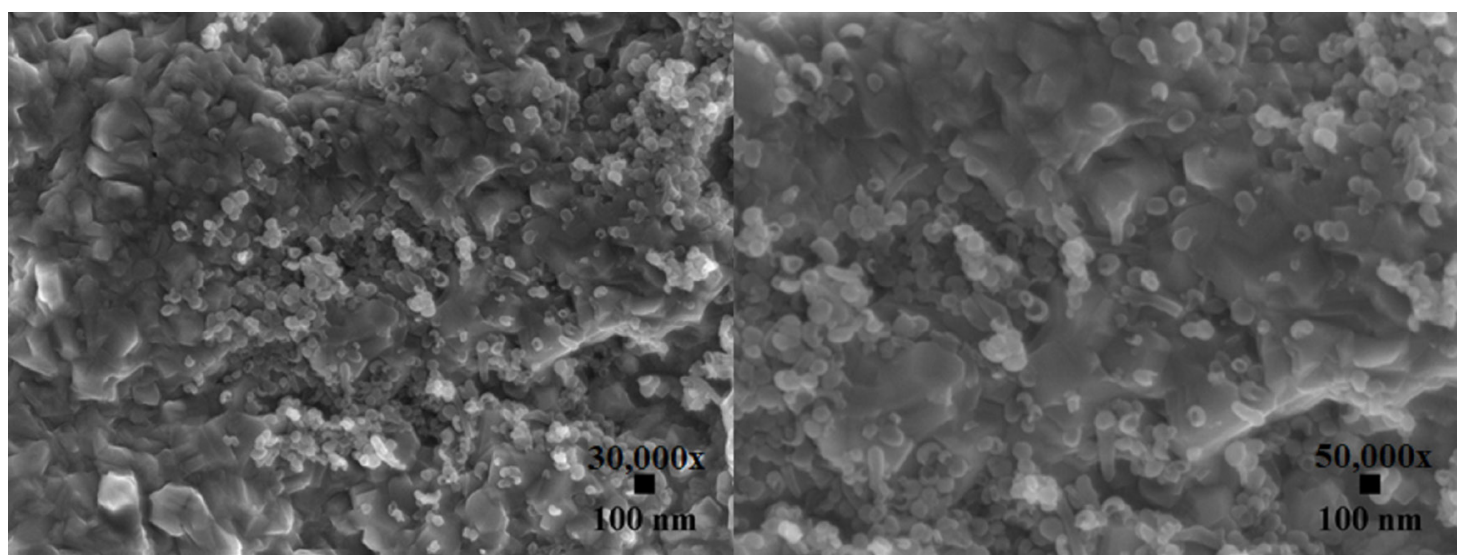

Figure 6. Nanopores and nanocrystals over the surface of anodized titanium with $\mathrm{HCl}$ at $15 \mathrm{~V}$ with a concentration of $0.15 \mathrm{M}$ in $60 \mathrm{~min}$ with a thermal treatment of $750{ }^{\circ} \mathrm{C}$ for $2 \mathrm{~h}$.

generated nanoporous agglomerations formed by anodization growing under the nanostructures as previously mentioned. The average grain cluster size was around $380 \pm 65 \mathrm{~nm}$.

\subsection{Structural analysis by X-Ray diffraction}

According to the X-ray diffraction analysis, the composition of the phases of the anodized titanium plates was obtained before and after the thermal oxidation process, which are shown in Figures 7 and 8. A qualitative analysis was done (PDF 00-044-1294, PDF 00-004-0551, PDF 01-071-1166) to study the present stages on the generated oxide layer. In Figure 7 the anodized samples without thermal oxidation showed a surface with very low crystallinity, so it was not possible to observe the anatase and rutile phases in the coatings. 


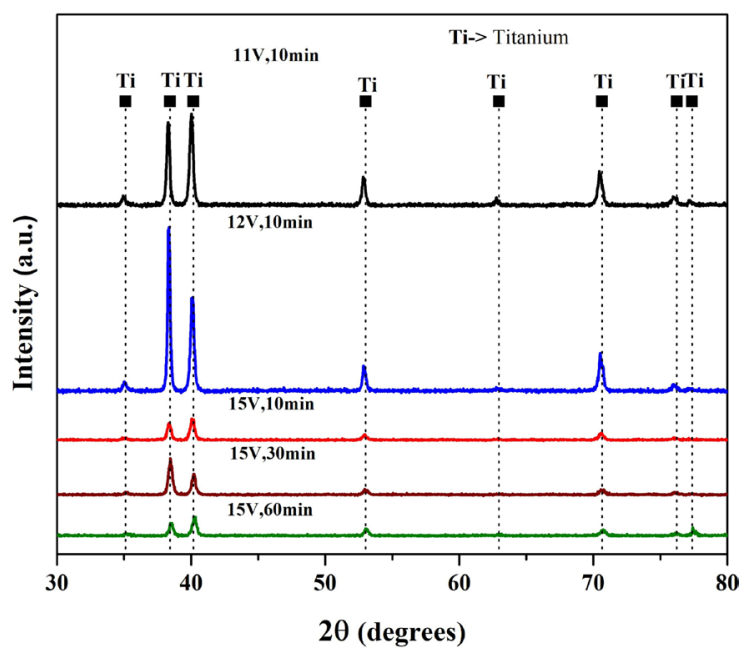

Figure 7. X-Ray diffraction patterns on the anodized titanium surface without thermic treatment.

However, when they were treated at temperatures of $750^{\circ} \mathrm{C}$, it was possible to visualize the anatase and rutile phases in the coatings, as can be observed in Figure 8. According to the literature consulted, when the process of electrochemical anodization and heat treatment is carried out, it is possible to obtain the anatase phase ${ }^{20}$, while, when titanium is subjected to thermal oxidation at higher temperatures without previously modifying its surface by any technique synthesis such as sol-gel or electrochemical anodization, it is only possible to obtain the rutile phase ${ }^{1,2,16-18,21}$.

The $\mathrm{TiO}_{2}$ with rutile form was observed with crystallographic direction it appeared with the thermal treatment process of $750{ }^{\circ} \mathrm{C}$ for $2 \mathrm{~h}$, the same way as the anatase phase was shown after a thermal treatment process. We observed that the anatase phase did not disappear despite it being subjected to a thermal treatment at a high temperature $\left(750^{\circ} \mathrm{C}\right)$, this is because some nanopores from the nanostructured surface began to take the form of a nanotube with very small longitudinal walls, however, according to the literature we consulted, the reasons that the anatase phase in the nanotube wall prevents the phase transition of the rutile crystal structure are as follows: (i) thermodynamic stability of the titanium anatase phase in small crystals, (ii) the average superficial energy of a crystal in the anatase phase is less than that of a crystal in the rutile phase and (iii) the great restrictions imposed by the tube walls create the necessary radiuses for rutile nucleation to be very big $^{22}$, which corroborates with the diffractograms in Figure 8.

The crystal size of rutile $\mathrm{TiO}_{2}$ with crystallographic orientation (110) was calculated by the Scherrer formula ${ }^{23}$, where changes in the size of the small crystal according to the changes in anodizing times can be observed. Table 1 shows the results obtained from the crystal size values of the adjustments made using the GaussAmp mathematical model ${ }^{24}$.

\subsection{Analysis by UV-Vis spectrometry}

The procedure to calculate the Band Gap of the heat treated anodized samples consisted from the Tauc-Plot

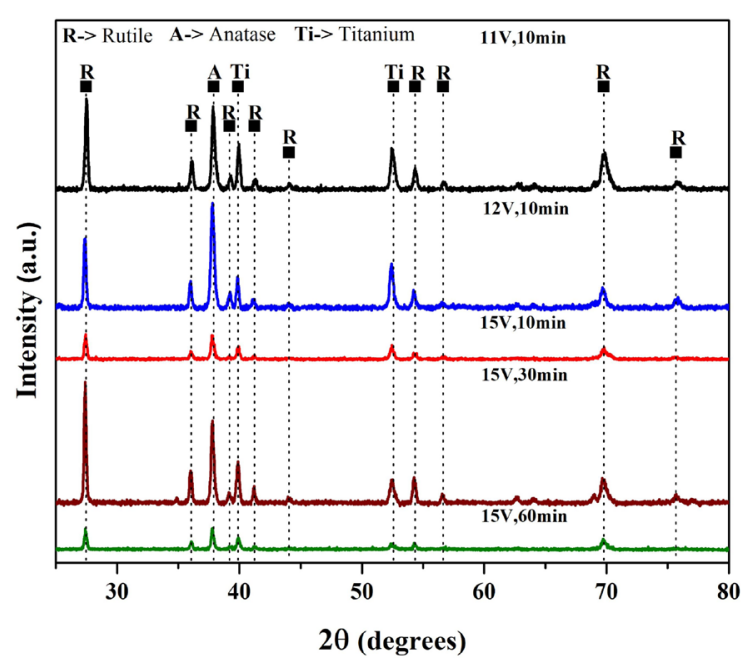

Figure 8. X-Ray diffraction patterns on the anodized titanium surface with thermic treatment at $750{ }^{\circ} \mathrm{C}$ for $2 \mathrm{~h}$.

Table 1. Size of the small crystal from the rutile peaks with orientation (110).

\begin{tabular}{lcc}
\hline Concentration & Conditions & $\begin{array}{c}\text { Crystallite Size } \\
(\mathrm{nm}) \text { Rutile }(110)\end{array}$ \\
\hline $\mathbf{3 M}$ & $11 \mathrm{~V}, 10 \mathrm{~min}$ & 32 \\
\cline { 2 - 3 } & $12 \mathrm{~V}, 10 \mathrm{~min}$ & 35 \\
\hline $\mathbf{0 . 1 5 M}$ & $15 \mathrm{~V}, 10 \mathrm{~min}$ & 34 \\
\cline { 2 - 3 } & $15 \mathrm{~V}, 30 \mathrm{~min}$ & 39 \\
\cline { 2 - 3 } & $15 \mathrm{~V}, 60 \mathrm{~min}$ & 34 \\
\hline
\end{tabular}

$\operatorname{method}^{25,26}$. From the absorbance data, the bandgap energy was calculated based on Equation 1:

$(\alpha h v)=A\left(h v-E_{g}\right)^{n}$

where $\mathrm{E}_{\mathrm{g}}$ is the band gap energy, $\mathrm{h}$ is Planck's constant, $v$ is frequency of vibration, $h v$ is the photon energy, A is a proportionality constant, $\alpha$ is the absorption coefficient and finally $n$ is 0.5 and 2.0 for a direct and indirect transition respectively, where, for the analysis of the coatings, a value of $n=2$ was used to estimate the Band Gap value in indirect transition. Figure 9a shows the optical absorbance and Figure $9 \mathrm{~b}$ presents the plot of $(\alpha \mathrm{hv})^{2}$ versus the absorbed light energy of the anodized sample at $15 \mathrm{~V}, 30$ min with heat treatment at $750^{\circ} \mathrm{C}$.

Table 2 shows the Band Gap values obtained, it can be seen that despite applying an increase in voltage for the anodized samples at a concentration of $3 \mathrm{M}$, the variation in Band Bap was not significant. While for the samples anodized at $0.15 \mathrm{M}$ with an applied voltage of $15 \mathrm{~V}$ with time variation, no significant changes were observed in the Band Gap, likewise, there was no correlation of the Band Gap values with respect to the different anodization conditions.

It has been reported that variations in Band Gap values are attributed to changes in annealing temperature ${ }^{27}$, therefore, this corroborates that despite obtaining different morphologies in 

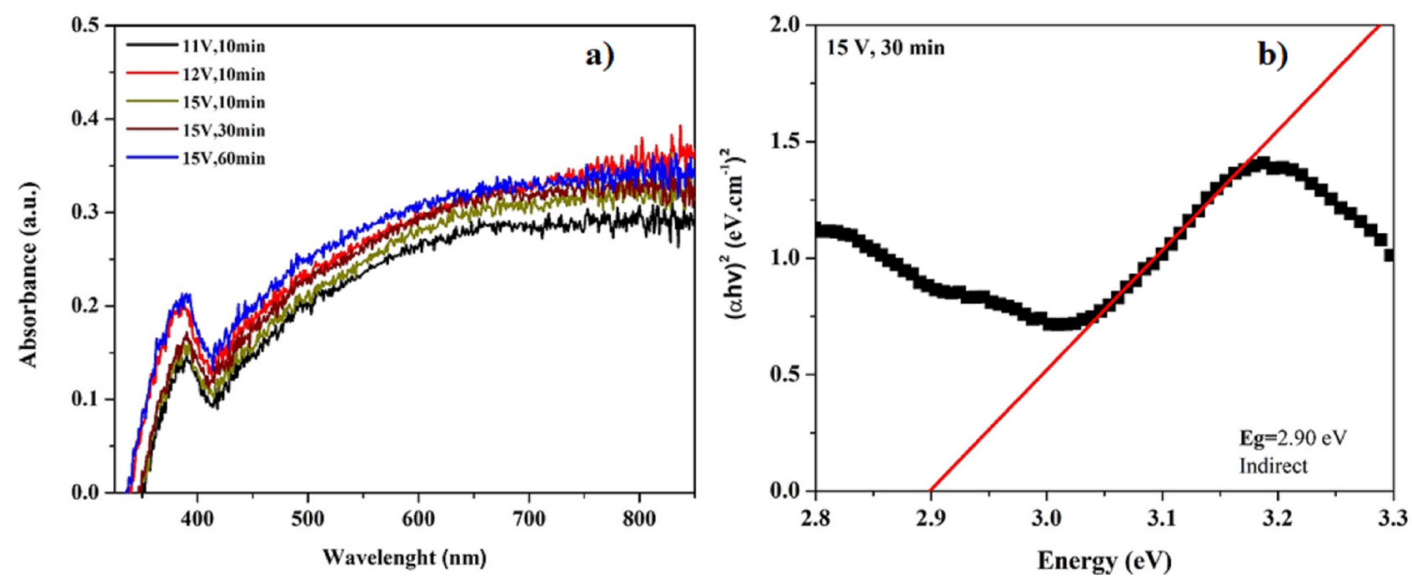

Figure 9. a) Absorption spectra from the titanium anodized samples with thermal treatment at $750{ }^{\circ} \mathrm{C}$ and b) calculation of the indirect band gap value by Tauc Plot method.

Table 2. Band Gap Values obtained through absorbance with the Tauc-Plot method with the thermally treated anodized samples.

\begin{tabular}{lcc}
\hline Concentration & $\begin{array}{c}\text { Electrochemical anodization } \\
\text { with Heat Treatment }\left(750^{\circ} \mathrm{C}\right)\end{array}$ & $\begin{array}{c}\text { Band Gap } \\
(\mathrm{eV})\end{array}$ \\
\cline { 2 - 3 } $\mathbf{3 M}$ & $\mathbf{1 1 V}, \mathbf{1 0 m i n}$ & $2.92 \pm 0.50 \%$ \\
\hline $\mathbf{0 . 1 5 M}$ & $\mathbf{1 2 V}, \mathbf{1 0 m i n}$ & $2.93 \pm 1.40 \%$ \\
\cline { 2 - 3 } & $\mathbf{1 5 V}, \mathbf{1 0 m i n}$ & $2.91 \pm 1.60 \%$ \\
\cline { 2 - 3 } & $\mathbf{1 5 V}, \mathbf{3 0 m i n}$ & $2.90 \pm 0.60 \%$ \\
\hline
\end{tabular}

Table 3. Thicknesses of the anodized samples with a thermal treatment of $750^{\circ} \mathrm{C}$ obtained with profilometry.

\begin{tabular}{ccccc}
\hline \multicolumn{2}{c}{ Concentration at $3 \mathrm{~mol} / \mathrm{L}$} & & \multicolumn{2}{c}{ Concentration at $0.15 \mathrm{~mol} / \mathrm{L}$} \\
\cline { 1 - 2 } Conditions & Thickness $(\mu \mathrm{m})$ & & Conditions & Thickness $(\mu \mathrm{m})$ \\
\hline $\mathbf{1 1 V}, \mathbf{1 0 m i n}$ & 6.5 & & $\mathbf{1 5 V}, \mathbf{1 0 m i n}$ & 5.5 \\
\hline $\mathbf{1 2 V}, \mathbf{1 0} \mathbf{m i n}$ & 10 & $\mathbf{1 5 V}, \mathbf{3 0 m i n}$ & 15 \\
\hline & & $\mathbf{1 5 V}, \mathbf{6 0 m i n}$ & 16 \\
\hline
\end{tabular}

titanium oxide coatings under different anodizing conditions and with a heat treatment temperature at $750{ }^{\circ} \mathrm{C}$, there were no significant changes in the optical absorption spectra.

\subsection{Thickness analysis though profilometry}

For thermally treated anodized samples, the profilometry technique was used ${ }^{28}$. For this measurement process, it consisted of removing the oxide layer using concentrated HF to generate a step to measure the thickness of the coatings ${ }^{29}$. Table 3 shows that for the samples anodized at $3 \mathrm{M}$ for $10 \mathrm{~min}$, the increase in voltage influenced the increase in thickness. Similarly, for the samples anodized at $0.15 \mathrm{M}$ and $15 \mathrm{~V}$, the variation of the anodization time favored the increase of the thickness on the titanium surface. Therefore, these changes in thickness values under the same heat treatment temperature $\left(750{ }^{\circ} \mathrm{C}\right)$ can be attributed to the voltage or to the anodizing time. Table 3 shows the values of the obtained thicknesses with the aforementioned technique.

The highest thickness value was $16 \mu \mathrm{m}$ in regard to the time variation, and the highest thickness value was
$10 \mu \mathrm{m}$ in regard to concentration variation. In accordance with reported studies, with the electrochemical anodization technique used in order to obtain $\mathrm{TiO}_{2}$ coating with nanotubes for biomedical applications, thicknesses from 22 to $34 \mu \mathrm{m}$ were obtained ${ }^{30}$.

\section{Conclusions}

Using aqueous solution $\mathrm{HC} 1$ as an electrolyte favors nanoporous surface formation. In addition, the time and voltage of anodization promotes nanoporous formation all over the surface of the material. The heat treatment did not modify the morphology of the nanostructures despite being subjected to high oxidation temperatures. It was observed that at $750{ }^{\circ} \mathrm{C}$ it promoted the growth of titanium oxide grains, which grew under the nanostructures that were previously obtained by anodizing. Electrochemical anodization favored the appearance of two crystalline phases, the first being the rutile phase with orientation (110) and the second being the anatase phase with orientation (004). It was found that working with a heat treatment temperature on the $\mathrm{TiO}_{2}$ nanostructured coatings did not present significant variations in the Band Gap values. Voltage and anodizing time significantly influence the growth in thickness of the oxide layer in such a way that it is possible to obtain values of up to $16 \mu \mathrm{m}$ with thermal treatment after the anodizing process.

\section{Acknowledgments}

Thanks to Doctorado en Materiales y Nanociencia del Centro de Investigación en Micro y Nanotecnología de la Universidad Veracruzana. This paper is supported by the CONACYT through scholarship 733061.

\section{References}

1. Aniolek K, Kupka M, Barylski A, Dercz G. Mechanical and tribological properties of oxide layers obtained ontitanium in the thermal oxidation process. Appl Surf Sci. 2015;357:141926.

2. Aniołek K, Kupka M, Barylski A. Sliding wear resistance of oxide layers formed on a titanium surface during thermal oxidation. Wear. 2016;356-357:23-9. 
3. Dikici T, Yildirim S, Yurddaskal M, Erol M, Yigit R, Toparli $\mathrm{M}$, et al. A comparative study on the photocatalytic activities of microporous and nanoporous $\mathrm{TiO}_{2}$ layers prepared by electrochemical anodization. Surf Coat Tech. 2015;263:1-7.

4. Munirathinam B, Pydimukkala H, Ramaswamy N, Neelakantan L. Influence of crystallite size and surface morphology onelectrochemical properties of annealed $\mathrm{TiO}_{2}$ nanotubes. Appl Surf Sci. 2015;355:1245-53.

5. Grimes $\mathrm{C}$, Mor $\mathrm{G}$, editors. $\mathrm{TiO}_{2}$ nanotube arrays: synthesis, properties, and applications. New York: Springer; 2009.

6. Su Z, Zhou W. Formation, morphology control and applications of anodic $\mathrm{TiO}_{2}$ nanotube Arrays. J Mater Chem. 2011;21(25):8955-70.

7. Chen X, Schriver M, Suen T, Mao S. Fabrication of $10 \mathrm{~nm}$ diameter $\mathrm{TiO}_{2}$ nanotube arrays by titanium anodization. Thin Solid Films. 2007;515(24):8511-4.

8. Richter C, Panaitescu E, Willey R, Menon L. Titania nanotubes prepared by anodization in fluorine-free acids. J Mater Res. 2007;22(6):1624-31.

9. Richter C, Wu Z, Panaitescu E, Willey RJ, Menon L. Ultrahighaspect-ratio titania nanotubes. Adv Mater. 2007;19(7):946-8.

10. Nguyen Q, Bhargava Y, Devine T. Titania nanotube formation in chloride and bromide containing electrolytes. Electrochem Commun. 2008;10(3):471-5.

11. Hassan F, Nanjo H, Venkatachalam S, Kanakubo M, Ebina T. Effect of the solvent on growth of titania nanotubes prepared by anodization of Ti in HCl. Electrochim Acta. 2010;55(9):3130-7.

12. Hernández-Montiel S, García-González L, Araujo Pérez DJ, Hernádez-Torres J, Zamora Peredo L, Maytorena-Sánchez A, et al. Structural analysis, tribological and hardness of titanium Grade 2 anodized, using HCI and ethylene glycol as electrolytic solution. ECS Trans. 2019;94(1):239-50.

13. Allam N, Grimes C. Formation of vertically oriented $\mathrm{TiO}_{2}$ nanotube arrays using a fluoride free $\mathrm{HCl}$ aqueous electrolyte. J Phys Chem C. 2007;111(35):13028-32.

14. Allam N, Shankar K, Grimes C. Photoelectrochemical and water photoelectrolysis properties of ordered $\mathrm{TiO}_{2}$ nanotubes fabricated by $\mathrm{Ti}$ anodization in fluoride-free $\mathrm{HCl}$ electrolytes. C J Mater Chem. 2008;18(20):2341-8.

15. Yoon Y, Park J. The effects of nanostructures on the mechanical and tribological properties of $\mathrm{TiO}_{2}$ nanotubes. Nanotechnology. 2018;29(16):165705.

16. Aniołek K, Kupka M, Barylski A, Mieszczak L. Characteristic of oxide layers obtained on titanium in the process of thermal oxidation. Arch Metall Mater. 2016;61(2):853-6.

17. Aniolek K. The influence of thermal oxidation parameters on the growth of oxide layers on titanium. Vacuum. 2017;144:94-100.

18 Aniołek K, Kupka M, Barylski A. Characteristics of the tribological properties of oxide layers obtained via thermal oxidation on Titanium Grade 2. P I Mech Eng J-J Eng. 2018;1-14.
19. Cetiner D, Paksoy A, Tazegul O, Atar E, Cimenoglu H. Characterization of thermally oxidized titanium based coating. J Achiev Mater Manuf Eng. 2016;75(2):49-54.

20. Cheong Y, Beh K, Yam F, Hassan Z. Performance evaluation of titanium dioxide based dye sensitized solar cells under the influence of anodization steps, nanotube length and ionic liquid-free redox electrolyte solvents. Superlattices Microstruct. 2016;94:74-84.

21. Sun F, Hu J. Effect of thermal oxidation on the combined performances of TA2. Mater Sci. 2014;11:120-4.

22. Fahim NF, Sekino T, Morks MF, Kusunose T. Electrochemical growth of vertically-oriented high aspect ratio titania nanotubes by rabid anodization in fluoride-free media. J Nanosci Nanotechnol. 2009;9(3):1803-18.

23. Al-Tabbakh A, Karatepe N, Al-Zubaidi A, Benchaabane A, Mahmood N. Crystallite size and lattice strain of lithiated spinel material for rechargeable battery by X-ray diffraction peak-broadening analysis. Int J Energy Res. 2019;43(5):190311.

24. Wu H, Hao X, Xu P, Hu J, Jiang M, Shaaban M, et al. CO and $\mathrm{N}_{2} \mathrm{O}$ emissions in response to dolomite application are moisture dependent in an acidic paddy soil. J Soils Sediments. 2020;20(8):3136-47.

25. Shkir M, Ganesh V, Yahia I, AlFaify S. Microwave-synthesis of $\mathrm{La}^{3+}$ doped $\mathrm{PbI}_{2}$ nanosheets (NSs) and their characterizations for optoelectronic applications. J Mater Sci Mater Electron. 2018;29(18):15838-46

26. Momeni M, Ghayeb Y, Mohammadi F. Solar water splitting for hydrogen production with $\mathrm{Fe}_{2} \mathrm{O}_{3}$ nanotubes prepared by anodizing method: effect of anodizing time on performance of $\mathrm{Fe}_{2} \mathrm{O}_{3}$ nanotube arrays. J Mater Sci Mater Electron. 2015;26(2):685-92.

27. Ennaceri H, Boujnah M, Taleb A, Khaldoun A, Sáez-Araoz R, Ennaoui A, et al. Thickness effect on the optical properties of $\mathrm{TiO}_{2}$-anatase thin films prepared by ultrasonic spray pyrolysis: experimental and ab initio study. Int J Hydrogen Energy. 2017;42(30):19467-80.

28. Wei C, Chang C. Polycrystalline $\mathrm{TiO}_{2}$ Thin films with different thicknesses deposited on unheated substrates using RF magnetron sputtering. Mater Trans. 2011;52(3):554-9.

29. Maytorena-Sánchez A, Hernández-Torres J, López-Huerta F, Hernández-Campos MA, Zamora-Peredo L, Pacio-Castillo $\mathrm{M}$, et al. Analysis of the hardness and tribological properties of grade 2 titanium using the thermal oxidation process at different temperatures. Mater Lett. 2021;282:128679.

30. Wu S, Wang S, Liu W, Yu X, Wang G, Chang Z, et al. Microstructure and properties of $\mathrm{TiO}_{2}$ nanotube coatings on bone plate surface fabrication by anodic oxidation. Surf Coat Tech. 2019;374:362-73. 